\title{
Engineers and engineering history: problems and perspectives.
}

\section{Citation}

Picon, Antoine. 2004. Engineers and engineering history: problems and perspectives. History and Technology 20, no.4: 421-436.

\section{Published Version}

doi:10.1080/0734151042000304367

\section{Permanent link}

http://nrs.harvard.edu/urn-3:HUL.InstRepos:10977386

\section{Terms of Use}

This article was downloaded from Harvard University's DASH repository, and is made available under the terms and conditions applicable to Other Posted Material, as set forth at http:// nrs.harvard.edu/urn-3:HUL.InstRepos:dash.current.terms-of-use\#LAA

\section{Share Your Story}

The Harvard community has made this article openly available.

Please share how this access benefits you. Submit a story.

\section{Accessibility}




\title{
ENGINEERS AND ENGINEERING HISTORY:
}

\section{PROBLEMS AND PERSPECTIVES}

\author{
Antoine Picon \\ Harvard University, Graduate School of Design
}

\section{INTRODUCTION}

In the past decades, the history of engineers and engineering has been marked by a spectacular development. Studies of the engineering profession in various countries ranging from England to Russia, from France to Egypt have multiplied. Engineering knowledge, as well as the various types of realizations it has led to, have been scrutinized by historians of science and technology.

Despite this development, the history of the engineers is still confronted to major interrogations. In addition, some possible directions of development have not yet been sufficiently explored. Above all, the relation between engineering history and social history is still an open-ended issue. What can we learn through engineering evolution that concerns society and culture at large? In the following 
pages, I would like to discuss some of these questions, as well as the perspectives of further inquiries that they imply. Among these perspectives, I will explore in particular the interest of notions such as rationality and social imagination in order to understand some key features of engineers and engineering history.

\section{ENGINEERS AND/OR ENGINEERING HISTORY}

Is the history of engineers primarily about the engineering profession and its evolution, or should it take into account its activities and realizations? Although the question might seem trivial at first, the answers given to it are quite different from one author to the other. Whereas some historians have tried to articulate these two dimensions, many have devoted themselves exclusively either to the social dimension of the engineers' history, or to its technical aspects. In the French case, historians and sociologists like André Thépot or André Grelon, have focused primarily on engineering institutions like state corps of engineers, engineering schools and associations. They have paid a special attention to the sociological origins and trajectories of the engineers that they have studied without entering into the details of their realizations. These details can be found in another series of contributions. The historians of art and architecture Bertrand Lemoine and Bernard Marrey have described for instance the evolution of civil engineering, of bridge building in particular, while the historian of technology André Guillerme has analyzed the emergence and development of building technologies in the nineteenth century. There are few relations between these two 
types of inquiries. Such a split is by no means a French specificity. The same divorce can be observed in the United States, between studies of engineering institutions and social strategies, like Edwin T. Layton's classical analysis of the "revolt of the engineers", and technologically-oriented accounts like Tom F. Peters' Building the Nineteenth Century.

The lack of relations between these two fundamental aspects of the history of engineers is partly attributable to the extreme diversity of their jobs and realizations. Besides the distance that separates civil, mechanical or electrical engineering, engineers, since the second half of the nineteenth century at least, have occupied all kinds of positions between purely technical functions and management responsibilities. Engineering looks more like a continent marked by striking contrasts than like a unified field. On this continent, no self-evident link seems to exist between the organization of the profession and the various activities engineers are involved in. In this context, it may be tempting either to define the engineer through his social identity and aspirations or to limit oneself to a relatively narrow domain of technological expertise.

Although valid in themselves, these two options may generate however some dissatisfaction, just as the purely internal or external histories of science that have coexisted for a long time. Is it possible, in particular, to study the engineers without taking into account their competences and realizations? Various attempts have been made to justify such a choice. The American scholar Peter Whalley has argued, for instance, that the main characteristics of the engineer lies in his 
intermediary position between capital and labor, as a trusted employee, contrary to the other categories of workers in a company. The observation is of course to a large extent true. The nineteenth-century French state engineers enrolled in the utopian and proto-technocratic Saint-Simonian movement were already persuaded that their mission was to act as mediators between capital and labor. In the 1920s and 1930s, a similar idea was at the core of the technocratic ideals that flourished in both the United States and Western Europe. The characterization seems however too narrow to apply to every situation, especially in countries where the State has traditionally been a massive employer of engineers like France or Russia. Once again, the engineers are spread on a continent that cannot be that easily mapped.

There are indeed questions that seem more relevant to the political and sociological realm than to the technological one. One could be tempted to examine for example the existence of national engineering traditions in such a light. The contrasts between British, French, or German engineering professions are largely linked to political and social factors, from the respective roles played by the administrations of these countries to the different conceptions of authority and hierarchy that permeates their industrial organizations. As we have tried to show in a paper published a few years ago, the major difference between earlynineteenth-century British and French engineers lies neither in their scientific training, nor in the type of skills they displayed on the field. It has more to do with the perspective these engineers assigned at the time to their quest for technological competence and responsibility. Whereas British engineers tried to 
emulate the traditional professions, to appear as the equivalent of ministers, physicians, or lawyers in their domain, their French counterparts were looking for a more authoritarian conception, seeing themselves as almost political figures in charge of the public good. In spite of its emphasis on their different attitude towards science, Edna Kranakis' comparison between American and French engineers leads to a very similar type of explanation.

Is it nevertheless possible to leave entirely aside the technological dimension of engineering when one deals with national engineering traditions? Tom Hughes' comparison between the development of electricity in the United States, the United Kingdom and Germany tends to suggest the contrary. Even if political and social factors play key roles, they are indeed intertwined with technological determinations. Despite what its name suggests, the so-called "social construction of technology" has shown that, while technology is socially constructed, society and sociability are often shaped by technological organizations and objects. The "social construction of technology" is also about the technological construction of society. What may appear as purely political and social factors is often linked to technological determinations. To come back to the comparison between British and French early-nineteenth-century engineers, their different aspirations have definitely something to do with the type of technological competence they have respectively developed. In the British case, the engineering field is marked by a continuity between civil and mechanical engineering, a continuity that limits somewhat the pretension of the engineer, since he appears as a member of a larger community of technologists that includes machine- and instrument-makers. In 
France, on the contrary, from fortification to bridges and highways, engineering is primarily defined through the design and realization of large, state-initiated infrastructures. The French engineers' aspiration to set the standards of public good is inseparable from their isolation from other technical figures, and their monopoly on large-scale infrastructures.

\section{KNOWLEDGE AND PRACTICE}

In order to throw some light on the difficult question consisting to know what is exactly and engineer, instead of focusing on his social standing, many authors have paid attention to the existence of a relatively formalized body of knowledge that separates him from other technological figures. Indeed, from the Renaissance on, engineers have often insisted on the necessity to ground their practice on science. The title of the first major French treatise on fortification published by Jean Errard de Bar-le-Duc on the eve of the seventeenth century, La Fortification Démontrée, Fortification Demonstrated, is quite revealing in that respect. The desire to demonstrate is typical of the ambition to ground engineering on the firm soil of scientific knowledge. Throughout their long history, engineers have furthermore developed a science of their own, an engineering science the relations of which with mathematics, mechanics, physics and chemistry have been studied at length by a whole range of historians. 
More generally, engineers seem definable by their ambition to take their decisions according to a rigorous set of criteria, some of these criteria regarding natural phenomena, others having to do with the economic feasibility of their projects. Authors ranging from Alfred Chandler to Hélène Vérin, or Theodore Porter, have stressed the importance of their contribution, not only to mathematics and physics, but also to the emergence and development of modern management and economics.

The large number of studies devoted to engineering education, to engineering schools in particular, is among the most visible consequences of the accent that has been put on knowledge as a crucial feature of the profession. Books and articles have been in particular devoted to the major French educational institutions: the École Polytechnique, the École des Ponts et Chaussées, the École Centrale, the École Supérieure d'Électricité, the Écoles d'Arts et Métiers, to name some of them. Studies concerning engineering education in Germany, Switzerland, the Netherlands, Sweden, Russia or Egypt are also available. The trend is less pronounced for sure in the United Kingdom or in the United States, the reason being the less determining influence of schools and diplomas on the structures of the profession. The study of engineering education appears nevertheless as one of the most developed areas in the history of engineers and engineering.

In most cases, this development has not addressed however the key issue of the relation between education and practice. More generally, the attention paid to the 
engineers' formalized knowledge, to engineering mathematics and mechanics, to engineering economical and managerial principles, has not been accompanied by a thorough investigation of their real impact on practice. Between the formalized knowledge that can be traced through courses and treatises, and the everyday decisions made by engineers, there must be for sure some kind of intermediate know-how. This intermediate level is still to a large extent unexplored.

How does engineering formalized knowledge relate to engineering practice? Various historians have tried to bring forward elements of answer to this pending question. Their answers have generally followed two different ways. The first one is to relate engineering knowledge to more fundamental cultural structures, structures that are supposed to govern both reflection and action. Michel Foucault's episteme, or Thomas Kuhn's paradigm, are among the possible theoretical models for these attempts to highlight the deep structures allegedly common to engineering knowledge and practice. My past work on the French state engineers in charge of the construction of bridges and highways, les ingénieurs des Ponts et Chaussées, clearly belongs to that tendency, just as Konstantinos Chatzis study of the engineering practice of regulation in large-scale nineteenth- and twentieth-century networks. Hélène Vérin's broad picture of early modern engineering, La Gloire des Ingénieurs is also close to that orientation that she merges with philosophical reflections borrowing to the theories of decisionmaking and design initiated by Herbert Simon and pursued by the late Jacques Guillerme on the French-history-of-technology scene. 
A second way to treat the problem is to inspire oneself from deterministic sociological theories like Bourdieu's one. Bruno Belhoste's recent synthesis on the scientific and technological curriculum at the Ecole Polytechnique clearly belongs to that second line. His work is indeed strongly indebted to Bourdieu's notions of field and habitus. Instead of invoking deep cultural structures anterior to discourse and action, it relies on the assumption that education shapes the horizon of expectations of the individuals submitted to it, as well as their behavior in the concrete circumstances of their practice. In his analysis of the technocratic orientation of the graduate of the Ecole Polytechnique, Belhoste is also close to some aspects of David Noble's work on contemporary American engineering, with its implicit criticism of the authoritarian streak at work in large sectors of the profession. Deterministic sociological theories are hard to separate from political stances that owe still something to former Marxist critique of science and technology.

In the domain of industrial organization, the study of hierarchy and the protocols of command it relies upon provide useful clues on how to relate engineering knowledge and practice. One of the major functions of knowledge is indeed to stabilize hierarchy and command. Command protocols bear as for them the mark of the know-how I mentioned earlier as intermediary between formalized knowledge and practice. In the work of Yves Cohen, one of the major French representatives of the domain, the role of formalized engineering knowledge is however downplayed, in spite of the key importance given to it by the forefathers of industrial organization like Frederick Winslow Taylor. 
Finally, the most convincing answer to the difficult question of the relation between engineering knowledge and practice has perhaps been brought by the Science Studies and the Social Construction of Technology. Abandoning all kind of episteme, paradigm or habitus in favor of a closer scrutiny of what actually happens on technological scenes, they have often convincingly described the interactions between knowledge, decision-making and realization. Michel Callon's and Bruno Latour's studies of the engineering of the electric vehicle and the mass-transit project Aramis are exemplary in that respect. Instead of researching an overhanging point of view, they have adopted a more horizontal vision enabling them to grasp the chains, or rather the networks constituted by humans and objects, knowledge and actions.

One must however notice that these inquiries have been generally conducted on a very small scale, a scale reminiscent of the influence exerted initially by ethnomethodology on the nascent Science Studies. Above all, the Science Studies and the Social Construction of Technology have focused on moments of change, on process of innovation rather than the long periods of stability that characterizes technological systems. In other words, the key problem of technological regulation has been left aside. Yet, just like the evolution of large technological systems, the history of engineers and engineering appears as a complex maze of changes and continuities, of stability and instability. 


\section{CONTINUITIES AND DISCONTINUITIES}

At this stage, it is perhaps necessary to review briefly the major articulations that are currently put forward to describe the engineers and engineering history. Let us note from the start that some of these articulations, like the eighteenth-century trend towards professionalization do not correspond to a clear-cut technological change. The often-indirect nature of the links between engineering transitions and technological change adds a supplementary degree of complexity to the history of the engineers.

A first way to organize this history is to observe the successive steps leading to the contemporary engineering continent. One considers generally that the first recognizable figure of engineer appears at the Renaissance, at the intersection of two traditions. The European Renaissance engineer is the inheritor of both the medieval master-builder and the specialist of war engines that had appeared as an advisor of princes and kings towards the end of the Middle Age.

At the time he engineer is an isolated figure, an artist working for kings and princes just like painters, sculptors or architects. He will remain in that position until the second half of the seventeenth century, when great territorial states like France will begin to give their military engineers a uniform, thus paving the way for the emergence of a profession. 
The next step is the gradual professionalization of engineers. In France through State corps of engineers and schools, in England through professional associations. In France the process begins with the creation of the corps of the fortification engineers by the end of the seventeenth century. In England through professional associations, from the 1770 s on. Globally, between 1750 and 1850 the profession emerges. Two models: the French State engineer, the British civil one.

From the 1850 s on, diversification. A growing number of civil engineers in France. Above all, mechanical, then electrical, chemical engineering. A process that will gradually create the continent we are facing today.

This diversification is accompanied by a trend towards management. Already discernible in France around the 1850s-1860s. Chandler observes the same one in America.

In the twentieth century, the massification of the profession.

Now the art of the engineer, a slightly different story.

An art with two major aspects: civil engineering and construction, on the one hand, machine-building on the other. The Italian do the two. The French restrict themselves to the first aspect, contrary to England. 
The nineteenth century sees the explosion of engineering.

Engineering knowledge and science reveals other transition.

From a geometrical knowledge to an engineering science based on calculus. 1750-1850. A gradual connection between engineering knowledge and science, a connection that existed prior to that only in very specific fields such as balistics.

Links between the engineering sciences and economics around the same period.

From the $1880 \mathrm{~s}$ on, the organizational and managerial turn. Epitomized by Frederick Winslow Taylor.

Today might very well represent a new transition with the so-called information revolution. Actually, one of its results could very well be a new autonomy of design.

A perplexing history. With syncopated rythms.

It doesn't connect that evidently to the general history of science and technology, interpreted as a history of innovations. The scientific revolution has not much to do with engineering even if Shea has tried to relate Galileo to the engineering culture of its time. 
The first industrial revolution and engineering history are not as easy as it may seem to connect.

Strangely enough, the links are more evident with some political and social issues. The birth of modern civil service, the growing power of administrations, meritocracy. The rise of businessmen in politics, Christophe Charles.

Planning, technocracy, what Weber would have called rationalization.

It seems as a whole a very discontinuous history. But there are nevertheless continuities. Through institutions: the extroardinary persistance of the Ecole Polytechnique and the state corps.

Attitudes, the inheritage of military engineering in France, mathematics as a science of action.

Technological traditions: the French obsession with earthwork, from fortification to freeways.

Finally, the history of engineers and engineering seem to leave two questions unaddressed. The first one lies, strangely enough, with the often-indirect connection between engineering evolution and global technological change. It raises the issue of the exact contribution of engineers to the dynamic of technology, past their role as inventors, designers, or managers. A second 
question regards the ways one can make sense of the complex maze of continuities and discontinuities that characterize the history of engineers and engineering. Is there coherence somewhere in this overlap of long-standing traditions and spectacular transformations? As we have seen, neither the engineers' social standing nor their formalized knowledge seem fit to provide it. Their practice is as for it too diverse for that purpose. In the last section of this paper, I would like to explore another path towards a comprehensive interpretation of engineers and engineering history.

\section{RATIONALITY, SOCIAL IMAGINATION AND ETHICS}

Although the study of practice has become a sort of watchword in contemporary history of science and technology, I am not sure that it can provide a stimulating guideline for the study of engineers and engineering. Beside the extreme diversity of the engineer's activities that I have already mentioned, another reason to distance oneself from this orientation is provided by the engineers themselves. From the Renaissance on, engineers have almost constantly stressed their difference with according to them down-to-earth practitioners. Their various sciences, their aspiration towards managerial responsibilities, converge on that point.

The only common denominator to all the species of engineers that can be found throughout the centuries and in the various domains where actors consider 
themselves and are considered by others as engineers is perhaps the idea of a specific kind of a reason at work in their endeavors. Beyond its scientific connotation, the claim of Jean Errard de Bar-le-Duc to "demonstrate" fortification is quite typical of this quest for motives, for a specific kind of reason that would distinguish the engineers from other figures.

It is thus tempting to define the engineers through a certain kind of rational argumentation, either in design or in decision-making. In other words, the identity of the engineer might very well like in a certain type of rationality, prior to the knowledge he makes use of.

The everyday confrontation with representatives of the profession at large may reinforce this point of view. For what civil and electrical engineers, engineers engaged in purely technological enterprises and managers seem to share is a certain attitude, patterns of thought and action like the systematic decomposition of a complex problem into more elementary questions, or even a certain rigidity when dealing with issues to which clear-cut distinctions do not apply, social issues for instance.

At this stage, it is necessary to avoid to pitfalls. The first one lies in an overintellectualized conception of rationality. As far as engineers and engineering are concerned, rationality appears first and foremost as a guideline for action. Although engineering knowledge bears its imprint, it reveals itself primarily through the concrete practice of design, technological development and decision- 
making rather than in purely discursive structures. Thus, it might enable to overcome the gap between knowledge and practice.

A second pitfall consists in sticking to a fixed, ahistorical conception of rationality, as if engineers had stuck, throughout their long evolution, to the same principles of choice and action. To demonstrate something did not have the same meaning at the end of the sixteenth century, by the mid 1850s or today. Although the study of rationality may smooth out part of the discontinuities and breaks of engineers and engineering history, it does not erase some of its most fundamental transformations.

This last point suggests that rationality is not to be confused with logic at large. Contrary to logic, rationality is permeated by all sorts of historically determined factors.

In the same line of thought, contrary to a long tradition in the social sciences, when confronted with science and above all technology, rational behavior cannot be separated from the objectives it aims at. The distinction between the rationality of the ends, and the rationality of the means employed towards them, seems to me hard to sustain in the case of the engineers, despite a long tradition interpreting technology as the realm of an instrumental rationality impervious to its real ends. On the contrary, ends and means are in constant interaction. 
This constant interaction means that rationality is not synonymous with a crystalclear attitude consisting in the determination of the most appropriate means towards an end, whatever it is. In other words, rationality cannot be reduced to a sort of calculation. Ends and means do not follow similar paths. They are often somewhat contradictory. Their interaction is synonymous with perturbations that transforms rationality into something more muddy, so to say, than what one might expect a priori.

Another reason for this muddy nature lies in the fact that the engineer's rationality is not a pure individual conduct. It emerges in a context of interaction with other partners. Beside the other engineers, it has to take into account the existence of entrepreneurs and workers, even if it tries to set its own agenda. Rather than the result of a solitary exercise of the mind, rationality is the product of interaction, communication, and conflict.

For all these reasons, rationality is permeated by a whole set of elements that are usually considered as irrational. It includes desire and even impulses towards certain ends. It must allow for the uncertainties of communication and for conflict. Once again, rationality is neither crystal-clear nor straightforward. It appears often through ambiguous and twisted courses of action.

Let us not forget in passing that, as Hélène Vérin has brilliantly shown, trick and deceit were not foreign to the initial definition of the engineer. With its use of technology as an almost counter-natural power, engineering had something to do 
with cheating, especially in the conduct of war, contrary to the frank and open attitude of traditional chivalry. In that respect, the engineer was comparable to Ulysses, wandering in a strange and threatening world the dangers of which he had to conjure through tricks like the Trojan horse.

Now rationality has something to do with the adaptation of means to ends, even if this adaptation is seldom a pure matter of optimization. In the case of the engineers, the means have been abundantly studied, even if their mobilization has often been described as a smoother process than what it is in reality. Here I would like to elaborate rather on the ends. For it might very well be the ends that singularize the engineers rather than their mobilization of scientific and technological knowledge. Behind the ambition to "demonstrate engineering" lies perhaps a relatively specific type of ambition, an ambition extending far beyond the simple desire to gain or maintain one's social status and power.

This ambition might account for the recurring links between engineering conceptions and utopia from the Renaissance to the present. Strangely enough, the figure of the engineer has been often associated with utopian dreams, from the fantastic machines of sixteenth- and seventeenth-century utopian narratives to the technocratic streak of many twentieth-century fictions. From the nineteenth century on, engineers have been furthermore associated to many utopian movements, Saint-Simonianism and Fourierism in particular. Once again, the ends may play a more important role than what is usually assumed. 
What is the aim of technology for engineers, beside of course their selfpromotion? One might be of course tempted to interpret it in very general terms, as an almost metaphysical quest for domination. In such a perspective, the works of Heidegger or of the School of Frankfurt comes immediately to the mind. When they were not sticking to the old anthem of the progressive hero devoted to public good, historians of engineering have often, implicitly or explicitly, given into that sort of perspective, the engineer appearing then as an almost Faustian villain.

Leaving that dramatic angle aside, I would like here to pay attention to another dimension of engineering, namely its belief in a natural order that should be a permanent source of inspiration for men and their organizations. To be more specific, engineers have generally seen themselves as mediators between nature and man. Their task was supposed to make nature exploitable, thus humanizing it to a certain extent, while importing into the human realm principles of productivity present in the natural world.

Another general characteristic of engineering lies in its systematic use of images and metaphors in order to formulate what this general role of mediation means in practice. Engineers have always made an intensive use of visual references borrowed to the natural or the human worlds. Plants, animals, skeletons, machines, come to their mind when they try to approach what they aim at. Their utopian production is revealing in that respect with its abundance of organic or mechanical references, from the circulation of blood as a metaphor of 
infrastructures networks to the various motors supposed to bring a new prosperity to mankind.

At a given time, the system of these images can be called imagination, imaginaire in French. Since it deals primarily with nature and society, the engineers' imagination is intimately linked to the system of images that prevail in society at large; it appears as a component of social imagination.

Social imagination plays two roles: a role of exploration of a different and better future, a role of justification of the present state of society. On the one hand, it is close to utopia, on the other it functions like ideology, according to Mannheim or Ricœur vision. Engineers' imagination functions in the same way.

Rationality is inseparable from imagination. At the intersection of the two, one finds among others the key notions of effectiveness and efficiency.

Effectiveness and efficiency are culturally constructed notions. Just like the scientist, who does not consider that all demonstrations are equivalent, engineers at a given time are more prone to certain solutions than to others. The best solutions supposed to be both effective and efficient are inspired by representations of what really matters in nature.

In other papers, I have tried to sketch out some episodes of the history of efficiency and effectiveness. 
A geometrical or Vitruvian efficiency. Belief in an ordered, architectonic nature. The same principles to be found in society.

An analytic efficiency. The accent put on mobility, movement. The engineer as a facilitator of movement. Links with economics. A new engineering science.

Other turning points, by the end of the nineteenth century with industrial organization, today also.

The pursuit of effectiveness and efficiency has something ethical in it. Just like the pursuit of justice among lawyers. In a way, the best manner to understand engineers and engineering is according to the same kind of analysis as law and legal professions. 